\title{
Assessment of Hafr Albatin University female workers' knowledge and health related behaviors regarding osteoporosis
}

\author{
Reda Mhmoud Mohamed Hables* \\ Obstetrics and Gynecologic Nursing Department, Faculty of Nursing, University of Alexandria, Alexandria, Egypt
}

Received: December 16, 2018

Accepted: March 11, 2019

Online Published: March 29, 2019

DOI: $10.5430 /$ jnep.v9n7p94

URL: https://doi.org/10.5430/jnep.v9n7p94

\begin{abstract}
Background and aim: Osteoporosis is a global and preventable public health problem considered as a potentially life threatening condition and having negative effects on both health and economics. The aim of this study was the assessment of Hafr Albatin University female workers' knowledge and health related behaviors regarding osteoporosis.

Methods: A descriptive exploratory research design was implemented. Setting: The study was conducted in a college. The sample was of convenience. There were 352 women working at the college at the time of data collection. Tools: self-administrative questionnaire consisted of three parts: Part I: sociodemographic data, Part II: women's osteoporosis health related behaviors. Part III: knowledge related to osteoporosis.

Results: About 50.9\% of the participants had moderate level of overall knowledge about osteoporosis. Only $13.7 \%$ of the participants reported the source of their knowledge was a physician. Regarding osteoporosis related health behaviors, less than one third (29.7\%) of the participants were consuming foods rich in calcium, but the majority of them consumed this food only 1-2 time per week and $30.3 \%$ of them were exposed to sunlight daily. $58.2 \%$ of the participants were drinking soda drinks daily and $83.4 \%$ were having coffee frequently.

Conclusions: Women had moderate level of overall knowledge about osteoporosis and there was a gap between knowledge and applying the related health behaviors. Where the women had information about the health and risk related behaviors but not follow this information in correct and accurate way. Recommendation: Prevention programmes should be designed to increase awareness of working women about osteoporosis. screening, prevention and treatment.
\end{abstract}

Key Words: Osteoporosis, Knowledge, Health behaviors, Women

\section{INTRODUCTION}

Osteoporosis is a chronic progressive disease and a major public health issue. World Health Organization (WHO) reported that osteoporosis is the epidemic of the 21st century. Osteoporosis is defined as a metabolic and skeletal disease characterized by decreased bone mass and microarchitectural deterioration of bone tissue, causing bone fragility and increasing the risk of fracture. ${ }^{[1,2]}$ Osteoporosis causes serious health and economic problems due to disability, poor quality of life, increased mortality and increased burden on the person, family and community due to and cost of treatment and disability. Osteoporosis affects mainly the older women, but the young women are also liable to develop this disease when exposed to risk factors. These factors

\footnotetext{
*Correspondence: Reda Mhmoud Mohamed Hables; Email: reda_hablas2005@yahoo.com; Address: Obstetrics and Gynecologic Nursing Department, Faculty of Nursing, University of Alexandria, Alexandria, Egypt.
} 
can be classified into controllable risk factors, such as low level of physical activity, low calcium and vitamin D intake smoking alcohol/caffeine soda uncontrollable factors, age, family history, ethnicity, postmenopausal status and small body frame. ${ }^{[3,4]}$

According to World Health Organisation, 22 million European and American women osteoporosis and 9 million fractures are attributed to osteoporosis every year. In Saudi Arabia, 10\% (2.5 million) of the healthy women 50 years of age and $2 \%(450,000) 70$ years are suffering osteoporosis. By 2050 , it is estimated the prevalence will increase to $31 \%$ (12.3 million) women 50 years and to $8 \%$ (3.2 million) in women at 70 years of age. ${ }^{[5,6]}$

Regarding Saudi Arabian women, the lifestyle factors have significant role in prevalence of osteoporosis. Limited sun exposure, vitamin-D deficiency and low calcium intake are common risk factors, albeit controllable The cornerstone of the prevention is the primary prevention, where women should be made aware of the risk factors. The primary prevention aims to ensure bone mineral density from an early age and maintenance of this bone mass in adulthood. That should be achieved through emphasizing on positive behaviors as appropriate intake of calcium and proteins, appropriate supplementation of vitamin $\mathrm{C}$ and $\mathrm{D}$, increase of physical exercises, decrease consumption of caffeine, soda and smoking. $[7,8]$

\subsection{Aim of the study}

The aim of this study was the assessment of university female workers' knowledge and health related behaviors regarding osteoporosis.

\subsection{Significance}

Osteoporosis is a significant global health issue: it is called a "silent killer" because of its slow onset and absence of symptoms. Its effects include disability, risk for fractures, mortality, loss of function, increased costs for the individual and the healthcare system. In The same time data about osteoporosis knowledge and prevention behaviors in Saudi Arabian women are scarce.

\subsection{Research question}

(1) Do female college workers have adequate knowledge about osteoporosis health related behaviors?

(2) What are their osteoporosis health related behaviors?

\section{SubJECTS AND METHOD}

\subsection{Research design}

Descriptive exploratory research designs was utilized.

\subsection{Setting}

The study was conducted at college of Hafer Albatin's university in Saudi Arabia.

\subsection{Sample}

This was a convenient sample of 352 female workers. All female workers who were available at the time of data collection and met the inclusion criteria were selected and included in the study. The inclusion criteria were:

- Female employees in a university.

- Willing to participate in the study.

\subsection{Tools}

Self-administered questionnaires were developed and utilized for data collection. They consisted of the following parts:

Part I: Basic data. This part was developed by the researcher. it entailed the following sections: First section, worker sociodemographic data such as: age, college, marital status, types of family and income). Second section, worker family history: if anyone in family suffering from medical diseases as diabetes, heart disease, kidney disease, osteoporosis or other, degree of relation in the family.

Part II: Osteoporosis Related Health Behaviors. ${ }^{[8]}$ It includes questions about dietary habits, calcium intake, coffee intake, soda intake, physical activity levels, sunlight exposure , blood examination for calcium. The women described their behaviors with a "yes" or a "no" and reported the frequency of each behavior.

Part III: Knowledge related to osteoporosis. ${ }^{[9]}$ This questionnaire was used by Winzenberg et al. to assess the knowledge related to osteoporosis but it was translated and culturally adapted into Arabic by the researcher(s). It contains 38 questions categorized in main subscales as follows:

- Knowledge regarding concept of osteoporosis (6 items).

- Knowledge regarding High risk factors (10 items).

- Knowledge regarding Signs and symptoms (7 items).

- Knowledge regarding Diagnosis and treatment (8 items).

- Knowledge regarding Preventive behaviors (7 items).

Each item was scored on a 3 point Likert format with the following coding: "do not know" (= 1 point), "disagree" (= 2 points) and "agree" (= 3 points), with total scores ranging from 38 to114. Higher scores indicate higher knowledge. 
The total scoring includes high knowledge, moderate knowledge, low knowledge as follows:

- $\geq 60$ low knowledge.

- 60-82 moderate knowledge.

- $<82$ high knowledge.

\subsection{Procedures}

The study was executed according to the following steps:

(1) An official letter from the dean of academic affair in university was attained after explain the purpose of the study.

(2) Tool (I) was developed by researcher after extensive review of recent and related literature. Tools (II) and (III) were chosen to measure the knowledge and health practices and were adopted by researcher after translation into Arabic language.

(3) The tools were validated by a jury of five experts in the related field.

(4) Tool's reliability was tested by Cronbach's alpha test and the result was satisfactory $89 \%$.

(5) A pilot study was conducted on 32 women, who were excluded from the main study. This was done to test the feasibility, clarity and applicability of the tools, as well as to calculate the time required to complete them. After the pilot study the tools were revised accordingly.

(6) For each recruited participant in the study the following issues were considered: gave an oral consent after explanations of purpose of the study. The confidentiality, privacy and right to withdraw at any time were secured.

(7) Each women was individually interviewed by the researcher using the interview questioner sheet.

(8) Data were analyzed with Microsoft Excel and Statistical Package for Social Science (SPSS), version 21.

\section{RESUlts}

Table 1 shows that more than one half $(53.5 \%)$ of the study participants were less than 30 year and only $3.7 \%$ of them more than 40 year. More than three quarters (79.3\%) of the study participants were married. Only $13.1 \%$ of the study participants had university education. In total $57.6 \%$ of the them had not a sufficient monthly income and lived in nuclear family $(71.6 \%)$.

According to Table 2, only $6.5 \%$ of the study participants had family history for medical disease, namely DM, hypertension, cardiac disease $(26.0 \%, 17.4 \%$ and $13 \%)$. The majority of family member who was suffering from medical disease was a mother and grandfather or grandmother $(62.2 \%$ \&
$56.5 \%$ ). As regarding history of osteoporosis, $15.9 \%$ of the study participants had relative with positive history to osteoporosis, usually the mother and grandmother $35.7 \% \& 28 \%$ respectively.

Table 3 illustrated that, more than two thirds $(84.1 \%)$ of the study participants was playing exercises. Where $50.1 \%$ of the them were exercising at 1-2 times/weekly. $29.7 \%$ of the study participants take calcium food, but $74.2 \%$ of them take this food only 1-2 times per week. $58.2 \%$ of the study participants drink soda drinks daily. The majority (83.4\%) of the study participants drink coffee frequently. As regards exposure to sun light, only $30.3 \%$ of the study participants exposed to sun light and $53.3 \%$ of them exposed only 1-2 times weekly. $75.1 \%$ of the study participants had heard about osteoporosis.

Table 1. Sociodemographic characteristics

\begin{tabular}{|c|c|c|}
\hline Socio-demographic data & $\mathbf{n}$ & $\%$ \\
\hline \multicolumn{3}{|l|}{ Age in years } \\
\hline$<30$ & 53 & 53.5 \\
\hline $30-<35$ & 153 & 43.3 \\
\hline $35-<40$ & 133 & 37.7 \\
\hline$\geq 40$ & 13 & 3.7 \\
\hline \multicolumn{3}{|l|}{ Mean: $28.5-41.6$ years } \\
\hline \multicolumn{3}{|l|}{ Marital status } \\
\hline Married & 279 & 79.3 \\
\hline Single & 73 & 20.7 \\
\hline \multicolumn{3}{|l|}{ Children } \\
\hline No & 309 & 87.8 \\
\hline Yes & 43 & 12.2 \\
\hline \multicolumn{3}{|l|}{ Education } \\
\hline Primary & 28 & 8.0 \\
\hline Secondary & 101 & 28.6 \\
\hline Diploma & 177 & 50.3 \\
\hline University & 46 & 13.1 \\
\hline \multicolumn{3}{|l|}{ College } \\
\hline Applied Medical Sciences & 87 & 24.7 \\
\hline Art and literacy & 105 & 29.8 \\
\hline Sciences & 160 & 45.5 \\
\hline \multicolumn{3}{|l|}{ Income } \\
\hline Not Enough & 203 & 57.6 \\
\hline Enough & 90 & 25.5 \\
\hline Enough and can save & 59 & 16.9 \\
\hline \multicolumn{3}{|l|}{ Types of family } \\
\hline Nuclear & 252 & 71.6 \\
\hline Extended & 100 & 28.4 \\
\hline
\end{tabular}


Table 2. Number and percent distribution of the Study Participants According to their family history

\begin{tabular}{lll}
\hline Medical history & n & \% \\
\hline Suffering from medical disease & 23 & 6.5 \\
Yes & 329 & 93.5 \\
No & & \\
Types of disease N = 23 & 5 & 17.4 \\
Hypertension & 4 & 17.4 \\
Cardiac & 3 & 13.0 \\
Renal & 6 & 26.0 \\
Diabetes mellitus & 5 & 21.8 \\
Others & & \\
Who is suffering from disease? & 8 & 34 \\
Father & 15 & 62.2 \\
Mother & 13 & 56.5 \\
Grandfather/grandmother & 3 & 13.0 \\
Sister/brother & 3 & 13.0 \\
Others & & \\
Relative suffering from osteoporosis & & 15.9 \\
Yes & 56 & 84.1 \\
No & 296 & \\
Degree of relation (N = 56) & & 35.7 \\
Mother & 20.5 \\
Father & 7 & 1.8 \\
grandmother & 15 & \\
Aunt & 13 & \\
Other (husband) & & \\
\hline & & \\
\hline
\end{tabular}

Figure 1 illustrates that slightly more than one half (50.9\%) of the study participants had moderate levels of knowledge regarding osteoporosis overall. Only $20.5 \%$ of them had high level of knowledge.

Figure 2 shows that almost half $(46.5 \%)$ of the participants had high levels of knowledge regarding the definition and concept of osteoporosis. While $52.7 \%$ and $35.7 \%$ of them had low levels of knowledge regarding signs and symptoms and diagnosis and treatment respectively. Regarding the knowledge about risk factors and preventive measures the participants had moderate levels of knowledge (43.9\% and $57.8 \%$ respectively).

\section{Discussion}

As osteoporosis is a public health problem among Saudi women, preventive measures at young adult age might be of interest to tackle this health condition. The aim of this study was to analyses lifestyle factors related to osteopenia and osteoporosis in young female Saudi women, in order to develop specific recommendations to help them develop adequate preventive behavior was first step for prevention. ${ }^{[10]}$

Table 3. Number and percent distribution of study participants according to their osteoporosis related behaviors

\begin{tabular}{lll}
\hline Osteoporosis related behaviors & $\mathbf{n}$ & $\mathbf{\%}$ \\
\hline Physical exercise & & \\
Yes & 294 & 83.5 \\
No & 58 & 16.5 \\
Type of exercises $=\mathbf{2 9 4}$ & & \\
Walking & 146 & 49.7 \\
Running & 27 & 9.2 \\
Wheel exercise & 90 & 30.7 \\
Housing activity & 31 & 10.4
\end{tabular}

Frequency of exercise $=294$

Daily $117 \quad 39.8$

$\begin{array}{lll}1-2 \text { weakly } & 177 & 60.2\end{array}$

Calcium intake

$\begin{array}{lll}\text { Yes } & 105 & 29.7\end{array}$

$\begin{array}{lll}\text { No } & 247 & 70.3\end{array}$

Frequency $=105$

$\begin{array}{lll}\text { Daily } & 27 & 25.7\end{array}$

1-2 weekly $\quad 78 \quad 74.3$

$\begin{array}{ll}\text { Soda consumption } & \\ \text { Yes } & 205\end{array}$

$\begin{array}{lll}\text { No } & 147 & 41.8\end{array}$

Frequency of soda consumption $=205$

Daily $170 \quad 82.9$

1-2 weekly $\quad 35 \quad 17.1$

Coffee consumption

$\begin{array}{lll}\text { Yes } & 293 & 83.2 \\ & 57 & 16.8\end{array}$

Frequency of coffee consumption $=\mathbf{2 9 3}$

Daily $230 \quad 78.5$

1-2 weekly $63 \quad 21.5$

$\begin{array}{lll}\text { Sunlight exposure } & & \\ \text { Yes } & 107 & 30.4\end{array}$

$\begin{array}{lll}\text { No } & 245 & 69.6\end{array}$

Frequency $=\mathbf{1 0 7}$

$\begin{array}{lll}\text { Daily } & 50 & 46.7 \\ 1-2 \text { weekly } & 57 & 53.3\end{array}$

Blood investigation for calcium

$\begin{array}{lll}\text { Yes } & 136 & 38.6\end{array}$

$\begin{array}{lll}\text { No } & 216 & 61.4\end{array}$

Causes

$\begin{array}{lll}\text { Regular } & 73 & 53.7\end{array}$

$\begin{array}{lll}\text { Back pain } & 22 & 16.2\end{array}$

Leg pain $\quad 17 \quad 12.5$

$\begin{array}{lll}\text { Easy fatigability } & 24 & 17.6\end{array}$

Results of investigation

Normal value $\quad 35 \quad 25.7$

Low value $\quad 101 \quad 74.3$

Attain Information regarding osteoporosis

$\begin{array}{lll}\text { Yes } & 265 & 75.3\end{array}$

$\begin{array}{lll}\text { No } & 87 & 24.7\end{array}$

Source of information

$\begin{array}{lll}\text { Relative/family } & 103 & 38.9 \\ \text { Media } & 57 & 21.5\end{array}$

$\begin{array}{lll}\text { Book } & 48 & 18.1\end{array}$

Medical staff $\quad 35 \quad 13.2$

\begin{tabular}{lll} 
Internet & 22 & 8.3 \\
\hline
\end{tabular} 


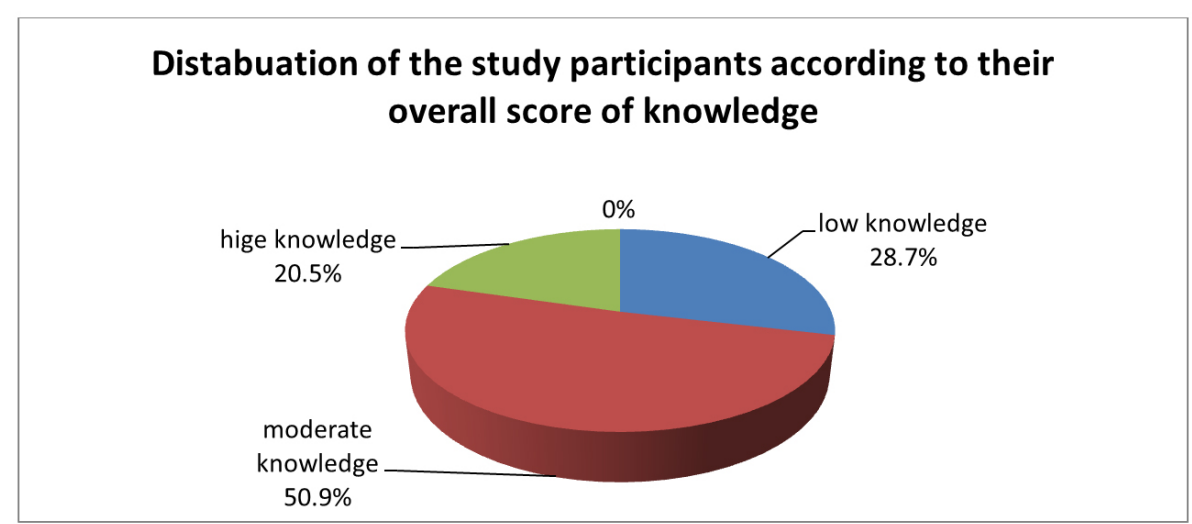

Figure 1. Distribution of the study participant according to their overall score of knowledge

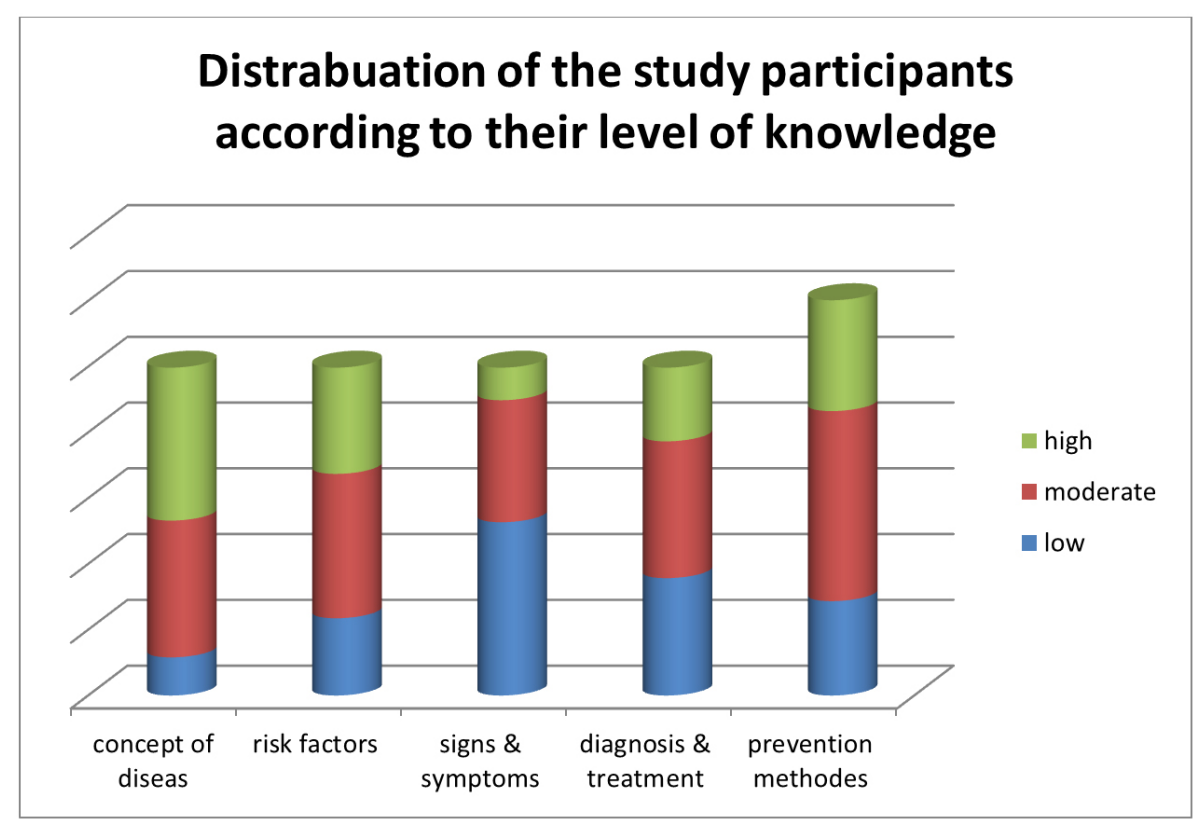

Figure 2. Distribution of the study participant according to their aspects of knowledge

This study aimed to assess and describe the female workers' knowledge regarding osteoporosis and health related behaviors. This study revealed that most participants were exercising once or twice per week (and mainly by walking), which is considered inadequate, as exercise should take place daily and include all types of exercise. The women knew that regular exercise can protect against osteoporosis, but this knowledge did not translate into practices due to culture consideration. In Saudi Arabia, women are require a guardian for commuting and the literature suggests a specific gender-based consideration when making recommendations to promote physical activity. Many factors hinder the participation of women in physical activity and their access to health care follow up, including lower income for women, required agreement from a senior member of the household to engage in physical activity, having a greater workload in the home and care-giving roles, limited mobility, and cultural restrictions. The social structure in Saudi Arabia tends to remain male-dominated, collectivistic, and patriarchal, with great emphasis on family values and group cohesiveness. Consequently, women who grow up in this kind of society may develop a lower internal sense of control and lower confidence level. This may carry even broader implications, since women will not play their important role in encouraging health behaviors in the family setting and on the community level. ${ }^{[11,12]}$

This result is similar with the results of Barzanji (2013) who reported that the majority of subjects had moderate levels of physical activity and the frequency and types of exercises did not fulfill the requirements to improve bone mass and increase bone mineral density. ${ }^{[13]}$ 
Regarding sun exposure, the majority of participants exposed to sun light only a little. This is due to the high temperatures in most days of the year, lack of awareness about optimal frequency and duration of exposure, and limited out-door activities. Saudi Arabia is considered as a sunny country. As the exposure from 10 to 15 minutes of sunlight for 3 times per week is considered enough to provide the body with adequate vitamin $\mathrm{D}$, The deprivation of sunlight may have consequences on bone mass. ${ }^{[14]}$

This study found that the majority of the study participants drinks soda daily. This is congruent with the results of Hossieni (2017) who found that Saudi Arabia citizens consume more soda drinks The soda drinks have negative consequences on the health in general and on bone health in particular, as they increase urinary calcium exertion and decrease calcium level in the blood, ultimately leading to osteoporosis. ${ }^{[15]}$

The current study revealed that one third of the study participants consume foods rich in calcium only once a week. Participants in the study reported remarkable low consumption of products rich in calcium. In another study the participants were not aware about the recommended calcium intake for adults and the different sources for calcium (Sidor 2016). This result also agrees with that by Al-Shahrani et al. (2015) who found that, the participants did not have adequate daily requirement from calcium intake. ${ }^{[16,17]}$

Regarding coffee consumption ,this study revealed that majority of women drank coffee very frequently. Excessive consumption of caffeine more than three cups per day lead to increase renal excretion of calcium and affects bone health. ${ }^{[18]}$

Half participants had moderate overall knowledge about osteoporosis. This finding in agreement with the results of Alanazi (2016), who stated that osteoporosis knowledge is not adequate to moderate. This is due to the fact that osteoporosis rarely considered as a public health issue not similar to cancer or infectious diseases, and is most prevalent among older, frail women. ${ }^{[19]}$

One third of the study participants had a high level of knowledge regarding prevention measures but alsohada gap between this knowledge and practical behaviors. This is in agreement with the findings in the study by Elsayed (2013), in which the majority of participants were able to identify risks of a lack of health related behavior but were unable to identify how to apply this into meaningful behaviors. ${ }^{[20]}$

Study participants had moderate level of knowledge related to risk factors. This finding is contradictory to that of a study done by Alshammari (2014) in which women indi- cated that their knowledge about osteoporosis risk factors was limited, irrespective of age, and the reason behind this was that women paid much attention to osteoporosis as a disease and its preventive measures. ${ }^{[21]}$

This study revealed that half of study participants had low knowledge about signs and symptoms of osteoporosis. This is because osteoporosis is a silent disease and develops slowly, so the symptoms get easily ignored, unless the person actually suffers from the disease (e.g., suffers from great pain) or presents with a fragility fracture. ${ }^{[22]}$

More than one third of the study participants had low level of knowledge related to treatment and diagnosis methods for osteoporosis. This result goes in line with that of Hosseine (2015), who reported that the majority of women were unaware about the therapy for osteoporosis. ${ }^{[23]}$ This is because all traditional curricula or elective courses and mass media focus on the physiology and pathology of osteoporosis and precipitating factors for osteoporosis. On the contrary, treatment is only discussed by the medical staff in the case of actual disease. This is consistent with findings by Alshammari (2014), where females perceived breast cancer and heart disease as greater threats than osteoporosis, as they believed susceptibility to osteoporosis was considerably lower their family. ${ }^{[14-21]}$

Three quarters of the study participants had obtained information about osteoporosis from relatives/family, media and books. Only a small proportion of them considered the physicians as sources of information. This result agrees with the study conducted by Zaki (2015), in which physicians were mentioned as the last source to gain information. This reflects cultural consideration: in Saudi Arabia the culture restricts the role of male doctor as an educator especially for women. This also reflects the need to empower physicians and nurses to undertake responsibility to increase the public awareness about osteoporosis. ${ }^{[2]}$ This is where a paragraph about the limitations of this study must be added.

\section{CONClusion}

Women had moderate level of overall knowledge about osteoporosis and there was a gap between knowledge and applying the related health behaviors. It seems that women have information about the health and risk related behaviors but not follow this information in correct and accurate way. The challenge remains in turning knowledge gained from health education into lifelong practices and adopting new health behaviors. Further research geared toward the follow-up of attained knowledge and behavioral change over time is needed. 


\section{Recommendations}

(1) Prevention programmers should be designed to increase awareness of university female worker about osteoporosis screening, prevention, and treatment.

(2) Taking steps to prevent osteoporosis early in life is vital through health education programs in the university as university activity.

(3) Appropriately trained health professionals such as physiotherapists, dieticians and nurses working along- side with the university teachers may be ideally placed to develop and provide such programs.

(4) Further research is needed regarding the effects of attained knowledge on behavioral changes over the time.

\section{CONFlicts OF InTEREST Disclosure}

The author declares that there is no conflict of interest.

\section{REFERENCES}

[1] Cech D. Prevention of osteoporosis: From infancy through older adulthood. Hong Kong Physiotherapy Journal. 2015; 30: 6-128. https://doi.org/10.1016/j.hkpj.2012.01.002

[2] Hammad L. Measurement of Bone Mineral Density and Stiffness Index in Young Sai Females. Pack Journal of Medical Sciences. 2016; 32(2): 399-402. PMid:27182248

[3] Al-Saleh Y, Sulimani R, Sabico S, et al. Guidelines for Osteoporosis in Saudi Arabia: Recommendations from the Saudi Osteoporosis Society. Annals Saudi Med. 2015; 35(1): 1-12. PMid:26142931 https://doi.org/10.5144/0256-4947.2015.1

[4] Ommen A, Alzahrani I. Prevalence of osteoporosis and factors associated with osteoporosis in women above 40 years in the Northern Part of Saudi Arabia. Int J Res Med Sci. 2014; 2(1): 274-278. https://doi.org/10.5455/2320-6012.ijrms20140252

[5] Alwahhabi B. Osteoporosis in Saudi Arabia. Saudi Med J. 2015; 36: 1149-1150. PMid:26446322 https://doi.org/10.15537/s $\mathrm{mj} .2015 .10 .11939$

[6] AlQuaiz A, Kazi A, Tayel S, et al. Prevalence and Factors Associated with Low Bone Mineral Density in Saudi Women: A Community Based Survey. BMC Musculoskeletal Disorders. 2014; 15: 5-15. PMid:24400907 https://doi .org/10.1186/1471-2474-15-5

[7] Al-Otaibi H. Osteoporosis Health Beliefs, Knowledge and Life Habits among Women in Saudi Arabia. Open Journal of Preventive Medicine. 2015; 5: 236-243. https://doi .org/10.4236/oj pm.2015.56027

[8] Kling J. Clarke B. Osteoporosis Prevention, Screening and Treatment: a review. J Women Health. 2014; 23(7): 4611.

[9] Winzenberg T, Oldenburg B, Frendin S, et al. The design of a valid and reliable questionnaire to measure osteoporosis knowledge in women: the Osteoporosis Knowledge Assessment Tool (OKAT). BMC Musculoskeletal Disorder. 2003; 4: 1-7.

[10] Oh S, Song B, Nam B, et al. Development and validation of osteoporosis risk-assessment model for Korean men. Yonsei Med J. 2016; 57(1): 187-96. PMid:26632400 https ://doi .org/10.3349/ymj 2016.57.1.187

[11] The International Osteoporosis Foundation (IOF). 2015. Available from: https://www.iofbonehealth.org/facts-and-stati stics/calcium-studies-map PMid:23780302

[12] Benajiba N, Hammad L. Lifestyle factors influencing Bone Health in young Adult Women in Saudi Arabia. African Health Sciences. 2017;
17(2): 524-531. PMid:29062349 https://doi.org/10.4314/ah s.v17i2.28

[13] Barzanji A, Alamri F, Mohamed A. Osteoporosis: A Study of Knowledge, Attitude and Practice among Adults in Riyadh, Saudi Arabia. Journal of Community Health. 2013: 38: 1098-1105.

[14] Amin S. Assessment of Knowledge Level on Osteoporosis among a Private University Students in Malaysia. Imperial Journal of Interdisciplinary Research. 2017; 3(3): 205-207.

[15] Hosseini Z, Karimi Z, Mohebi S, et al. Nutritional Preventive Behavior of Osteoporosis in Female Students: Applying Health Belief Model (HBM). Int J Pediatr. 2017; 5(1): 4137-44. https: //doi.org/10.22038/ijp.2016.7560

[16] Sidor P, Glabska D. Analysis of the Dietary Factors Contributing to the Future Osteoporosis Risk in Young Polish Women. Rocz Panstw Zakl Hig. 2016; 67(3): 279-285. PMid: 27546325

[17] Al-Shahrani F, Al-Zahrani A. Knowledge of Osteoporosis in M middle Aged and Elderly Women. Saudi Medical Journal. 2015; 31(6): 684-7.

[18] Mahboub S. Evaluation of the prevalence and correlated factors for decreased bone mass density among pre- and post-menopausal education working women in Saudi Arabia. Journal of Health Popular. 2014; 32: 513-519.

[19] Alanazi N, Alshahrani M. Osteoporosis Knowledge and Attitude Assessment among female university student in Tabuk, Saudi Arabi Indian Journal of Basic and Applied Medical Research. 2016; 5(4): 310-15.

[20] El-sayed M, Abdel megeid F. Osteoporosis-related life habits, knowledge and attitude among group of female employees in king Saud university. World Applied Sciences Journal. 2013; 22(7): 919-925.

[21] Alshammari K. Women Knowledge, Attitude and Practices about Osteoporosis Prevention (Riyadh Saudi Arabia). World Journal of Medical Sciences. 2014; 11: 422-31.

[22] Abdullah K. Awareness of Osteoporosis among Al-Ahsa Population, KSA. International Journal of Academic Scientific Research. 2016; 4(2): $10-19$.

[23] Hossein Y. Osteoporosis: Knowledge practices and prevention among female adolescent in El-Minia, Egypt. Journal of Nursing Research 2015; 3(4): 66-72.

[24] Zaki G. Awareness among student university in Jeddah, Saudi Areabia. Journal of Advanced Laboratory Biology. 2015; 5(2): 43-47. 